\title{
PENGARUH BUDAYA KOREA (K-POP) TERHADAP REMAJA DI KOTA CIREBON
}

\author{
Ida Ri’aeni, Musiam Suci, Mega Pertiwi, Tias Sugiarti. \\ ida.iswahyudi@gmail.com \\ Prodi S1 Ilmu Komunikasi \\ Universitas Muhammadiyah Cirebon \\ Kampus 2 UMC, Jl. Fatahillah No.10 Cirebon, Jawa Barat
}

\begin{abstract}
ABSTRAK
Berbagai produk budaya Korea mulai dari drama film, lagu, fashion, gaya hidup produk-produk industri mulai mewarnai kehidupan masyarakat di berbagai belahan dunia. Budaya Korea berkembang begitu pesatnya dan meluas serta diterima publik sampai menghasilkan sebuah fenomena demam Korean Wave. Budaya dan gaya hidup Korea (Hallyu atau Korean Wave) telah menjadi budaya populer yang menyebar ke berbagai negara termasuk Indonesia. Belakangan ini budaya Korea atau K-pop begitu mewabah pada remaja di Indonesia termasuk remaja di sekitar Kota Cirebon. K-pop tidak hanya soal musik, akan tetapi lebih terasosiasikan K-pop dengan semua budaya asal Korea. Adanya komunitas Dance Korea seperti Cirebon Kpop Dance Cover atau Cirebon Korean Dance Cover; Komunitas Fans K-Pop, seperti ARMYINA, ARMYCIR; Grup Online yang diikuti remaja seperti IKON, K-DRAMAS FOR LIVE, KIM TAEHYUNG, KOREAN DRAMA FANS; hingga Kedai Makan Korea seperti Haebaragi dan Epen's Box yang menyediakan hidangan seperti kimbab, ramyeon, bulgogi, kimchi, daenjang Jjiggae, bibimbap serta samyang. didapati beberapa remaja yang sejatinya menganggap budaya lokal atau nasional lebih disukai atau lebih mereka kenal, namun mereka pun tidak ingin ketinggalan mengikuti perkembangan sebagai penggemar budaya pop yang berasal dari Korea. Mereka beranggapan mengikuti perkembangan tersebut adalah sejalan dengan modernitas yang sedang marak.
\end{abstract}

Kata Kunci: Budaya K-Pop, Korean Waves, Remaja Cirebon, Budaya Cirebon. 


\section{A. PENDAHULUAN}

Saat ini perkembangan zaman semakin hari semakin modern diiringi dengan perkembangan teknologi yang semakin pesat. Hal tersebut diikuti dengan perkembangan media sosial dan internet yang dapat memudahkan beberapa orang mengakses informasi saling berkomunikasi, dan dapat mengetahui dunia luar tanpa berkunjung ke negara tersebut.

Tidak jarang banyak sekali anak usia dini pandai dan mahir dalam mengakses internet. Bahkan juga banyak anak di bawah umur memiliki akun-akun media soaial seperti Facebook, Twitter, Instagram dan sebagainya. Akun tersebut mempermudah anak-anak usia dini atau remaja untuk mengakses dunia luar seperti gaya hidup, fashion dan berbagai macam budaya yang telah mewabah di kehidupan remaja.

Perkembangan teknologi informasi khususnya media massa memberikan dampak yang sangat besar dalam kemajuan komunikasi. Teknologi yang canggih tidak hanya dapat menyebarkan informasi dengan cepat namun bermanfaat dalam memudahkan penyebaran informasi mengenai budaya dari seluruh dunia.

Penyebaran informasi pada media massa saat ini berkaitan dengan budaya populer atau dikenal sebagai budaya pop. Budaya pop secara sosiologis merupakan budaya yang sedang tren, banyak diminati dan cepat berganti. Kebudayaan populer biasanya berkaitan dengan masalah keseharian yang dapat dinikmati oleh semua orang atau kalangan orang tertentu, seperti musik, film, fashion, dan lain-lain (Bungin, 2006:100 dalam Riauzie Poetri, 2014). 
Korea Selatan menjadi salah satu negara yang mempopulerkan budaya pop saat ini. Aktor dan aktris serta musisinya lah yang berhasil "menyihir" berbagai kalangan. Budaya K-Pop pun menjadi mendunia. Termasuk kuliner dan budayanya.

K-pop, kepanjangannya Korean Pop ("Musik Pop Korea"), adalah jenis musik populer yang berasal dari Korea Selatan. Banyak artis dan kelompok musik pop Korea sudah menembus batas dalam negeri dan populer di manca negara.

Kegandrungan akan musik KPop merupakan bagian yang tak terpisahkan daripada demam Korea (Korean Wave) di berbagai negara. Musik pop Korea pramodern pertama kali muncul pada tahun 1930-an akibat masuknya musik pop Jepang yang juga turut mempengaruhi unsur-unsur awal musik pop di Korea (Simbar, 2016).

Berbagai produk budaya Korea mulai dari drama film, lagu, fashion, gaya hidup produk-produk industri mulai mewarnai kehidupan masyarakat di berbagai belahan dunia. Budaya Korea berkembang begitu pesatnya dan meluas serta diterima publik sampai menghasilkan sebuah fenomena demam Korean Wave (Simbar, 2016).

Indonesia termasuk negara yang sedang terkena demam Korea yang sudah hal ini dapat terlihat di layar televisi majalah dan juga internet di Indonesia yang sekarang berlomba-lomba untuk menayangkan atau menginformasikan seputar berita-berita Korea (Simbar, 2016).

Fenomena budaya Korean wave inilah yang membuat industri fashion Korea memasuki pasar di Indonesia terutama di kota besar seperti Jakarta. Jakarta sebagai pusat pemerintahan, namun juga menjadi lokasi yang strategis bagi pelaku industri seni dari luar Indonesia, termasuk Korea 
Selatan untuk berbisnis dan memperkenalkan kebudayaan yang dimiliki. (Riauzie Poetri, 2014).

Belakangan ini budaya Korea atau K-pop begitu mewabah pada remaja di Indonesia termasuk remaja di sekitar Kota Cirebon. K-pop tidak hanya soal musik, akan tetapi lebih terasosiasikan K-pop dengan semua budaya asal Korea. Seperti budaya barat dan budaya Jepang atau J-pop yang pernah menjangkit remaja Indonesia. Bukan hanya dari segi musik yang menjadikan Korea berpengaruh besar terhadap para remaja, namun terdapat juga dari sisi yang lain, seperti drama Korea, style Korea, dan lain-lain.

Sering para remaja begitu terobsesi dengan hal-hal yang berbau korea. Sehingga mereka tidak mengetahui perkembangan dunia entertaiment Indonesia, justru mereka lebih mengikuti dan antusisas dengan perkembangan dunia entertainment Korea, banyak dari mereka memilih gaya fashion ala Korea, mempelajari tulisan dan bahasa Korea tetapi tidak pernah mempelajari bahasa daerahnya sendiri. Bahkan di jejaring sosial banyak dari mereka yang mencantumkan beberapa kota di Korea Selatan sebagai kota tempat tinggal atau kota asalnya, banyak juga yang menggunakan nama Korea untuk nama jejaring sosial mereka.

Tentunya hal ini memberikan dampak bagi pembentukan mental remaja Indonesia. Para remaja seakan kehilangan jati dirinya dan lupa akan budayanya sendiri. Hal inilah yang memotivasi penulis untuk membahas kecenderungan remaja Indonesia, terutama remaja Kota Cirebon yang mengagumi budaya Korea (K-pop) yang menimbulkan demam dan sindrom Korea yang seringkali disebut Korean Wave. 
Berdasarkan latar belakang masalah, maka yang akan di bahas dalam penelitian ini adalah:

1. Bagaimana pengaruh budaya Korea (K-pop) terhadap remaja Kota Cirebon?

2. Bagaimana dampak yang ditimbulkan dari fanatisme budaya Korea (Kpop) terhadap remaja Kota Cirebon?

Berikut ini adalah manfaat penelitian ini:

1. Kegunaan Teoritis

a Memberikan kontribusi terhadap perkembangan ilmu-ilmu sosial, khususnya ilmu komunikasi yang berbasis pada pengembangan penelitian kajian budaya populer dan komunikasi massa.

b Dapat digunakan sebagai acuan bagi penelitian sejenis untuk tahap selanjutnya.

2. Kegunaan Praktis

a Penelitian ini diharapkan dapat menjadi landasan dalam memahami fenomena meluasnya budaya Korea (K-pop) akibat globalisasi dan cara menghadapinya melalui pemahaman-pemahaman.

b Penelitian ini diharapkan dapat menambah wawasan tentang pengaruh budaya Korea (K-pop) terhadap para penggemarnya.

\section{B. KAJIAN TEORITIS}

Kebudayaan mencakup keseluruhan sistem gagasan, tindakan dan hasil karya manusia dalam kehidupan masyarakat yang dijadikan milik diri manusia dengan belajar (Koentjaraningrat, 2009:144 dalam Simbar, 2016).

Definisi budaya dalam Kamus Besar Bahasa Indonesia adalah adat istiadat, sesuatu mengenai kebudayaan yang sudah berkembang. Konsumsi adalah sebuah perilaku aktif dan kolektif. Budaya konsumsi yang merupakan jantung dari kapitalisme adalaha sebuah budaya yang 
didalamnya terdapat bentuk halusinasi, mimpi, artifilsialitas, kemasan wujud komoditi, yang kemudian dikonstruksi sosial melalui komunikasi ekonomi (iklan, show, media) sebagai kekuatan tanda (semiotic power) kapitalisme. Budaya konsumsi merupakan suatu hal yang menarik untuk dikaji karena terkait dengan budaya pop karena budaya konsumsi ini mengacu seperti budaya pop yaitu bersifat massal. (Simbar, 2016).

Budaya dan gaya hidup Korea (Hallyu atau Korean Wave) telah menjadi budaya populer yang menyebar ke berbagai negara termasuk Indonesia. Jika melihat bagaimana budaya Korea menyebar di kehidupan masyarakat dunia memunculkan pertanyaan tentang kemungkinan Korean Wave membentuk minat dan perilaku konsumsi baru pada mereka yang memiliki minat pada produk-produk korea (Ridaryanthi, 2014).

Setelah melewati sejarah panjang penjajahan di Korea beberapa tahun silam, Korea mulai mengejar ketertinggalannya dengan berbagai usaha untuk mengembangkan dan memajukan negaranya. Perkembangan di Korea berpusat pada segala bidang, termasuk budaya. Korea mengadopsi banyak budaya negara lain seperti gaya hidup Amerika begitu pula dengan sistem pendidikannya, menerapkan filosofi budaya Eropa dan juga modernitas yang dianut oleh budaya Jepang (Korean Culture and Information Service, 2011: 17 dalam Ridaryanthi, 2014).

Semua aspek yang disebutkan tadi telah bercampur menjadi adonan baru pada budaya dan perkembangan kehidupan masyarakat Korea, yang mungkin sudah tidak asing lagi bagi seluruh penduduk dunia yang mengenalnya melalui media. (Ridaryanthi, 2014: 88).

Pada dasarnya Korean Wave atau Gelombang Korea adalah terjemahan dari istilah 한류 (Hallyu) dalam bahasa Korea yang artinya adalah 'arus 
Han'. “Han” ini sendiri mengacu pada Hankuk atau Korea. Sedangkan 류 berarti 'arus, aliran'. Istilah ini yang menciptakan adalah media massa dari Cina tempat asal muasal semua Hallyu 韓流 ini terjadi.

Korean wave diciptakan oleh media Cina kurang lebih sekitar belasan tahun lalu yang lalu dengan merujuk pada bagaimana populernya budaya Korean di China ketika drama Korea diekspor dan menjadi sangat booming pada masa itu (Korean Culture and Information Service, 2011: 9 dalam Ridaryanthi, 2014: 89).

Tepatnya saat pada tahun 1997 ada drama Korea yang pertama kali tayang di CCTV China. Drama ini berjudul 'What Is love All About' (사랑이워길래 Sarangi mwo gille). Dari sini banyak orang Cina yang suka dan akhirnya semakin banyak produk budaya (drama) Korea yang tayang di negeri Cina. Selain itu, pada saat yang sama ada grup boyband Korea, yaitu H.O.T. yang juga menjadi terkenal didaratan Cina. Jadi kombinasi terkenalnya drama dan musik Korea (istilah K-Pop saat itu belum ada) di Cina menjadikan media massa Cina memunculkan istilah ini. Dari situlah muncul istilah Hallyu. Setelah itu, Taiwan, Vietnam, Jepang dan negaranegara lain terimbas dan ikut mulai menyukai Hallyu.

Dari segi arti, maka Korean Wave atau Hallyu adalah fenomena mengalirnya budaya populerKorea (Selatan) ke dunia internasional. Hallyu adalah fenomena mengalirnya budaya populer Korea yang berupa drama, film, dan musik (K-Pop) yang diawali dari negara-negara serumpun (Cina, Taiwan, Jepang) dan Vietnam yang akhirnya merembet ke negara-negara Asia Tenggara lainnya hingga paruh pertama tahun 2000-an. 
Kemudian, Hallyu menyebar ke negara-negara Amerika Selatan, Timur Tengah dan sebagian Afrika hingga paruh kedua tahun 2000- an. Hingga akhirnya sampai ke seluruh dunia termasuk kawasan Eropa dan Amerika Serikat pada tahun-tahun terakhir dekade pertama abad ke-21 (thn 2000an akhir).

Hallyu sebagai aliran budaya populer Korea adalah sebuah fenomena yang saat ini terus berlangsung dan seperti halnya budaya populer Jepang yang mendahului sepak terjangnya di Asia dan dunia sejak tahun 1990an, Hallyu tidak bisa diprediksi sampai kapan berlangsung. Bahkan sekarang Hallyu pun meluas menjadi bukan hanya untuk menyebut mengalirnya budaya popular, tapi juga fashion, masakan dan industry kreatif lain dapat juga disebut hallyu. (Simbar, 2016).

Korean wave merepresentasikan bagaimana budaya melebur dan bahkan bergeser dari konstruksi asalnya menjadi konsep yang baru. Dalam penelitian ini, peleburan budaya kemudian menjadi wujud baru yaitu budaya populer. (Ridaryanthi, 2014).

Sirkulasi dan konsumsi film, mode, musik juga program televisi telah mampu memengaruhi budaya lokal dan regional di mana produk tersebut dikonsumsi. Indahnya pakaian a la tren artis Korea, wujud desain arsitek bangunan, swalayan dan tempat makan bernuansa budaya Korea digambarkan pada setiap drama seri yang menarik perhatian masyarakat global (Korean culture and information service, 2011: 27 dalam Ridaryanthi, 2014: 90).

Sarah Leung (2011) menyatakan bahwa K-Pop telah dengan sukses menghasilkan konstruksi citra, seksualitas, femininitas, maskulinitas dan moralitas yang baru pada masyarakat. Dengan kata lain, masyarakat 
dinyatakan cenderung dapat mengetahui dan mengidentifikasi nilai budaya yang dibawa oleh Korean wave tersebut melalui produk-produk yang beredar. Penggemar K-Pop pada akhirnya mencari tahu dan belajar banyak tentang budaya korea secara lebih luas lagi (Leung, 2011: 45 dalam Ridaryanthi, 2014).

Tomlinson (2005: 20) menyatakan bahwa motivasi seseorang dalam mengkonsumsi produk dapat dipengaruhi oleh gaya hidup yang berkaitan dengan kelas sosial. Pernyataan Tomlinson ini juga didukung oleh argumen Semenik et al. (2012: 178) yang menyatakan bahwa manusia mengkonsumsi sesuatu berdasarkan pada fungsi dan emosi yang berkaitan dengan kesenangan dan gaya hidup. Budaya melingkupi kreasi, transmisi, resepsi dan interpretasi dari iklan dan merek (Semenik et al., 2012: 196 dalam Ridaryanthi, 2014), ketika berelasi dengan konsumsi dan periklanan.

Di Indonesia, berkembangnya Korean Pop Culture diawali dengan kemunculan drama seri Korea terlaris kala itu yaitu Endless Love pada tahun 2002 di salah satu stasiun televisi swasta. Cerita yang dikemas secara apik, tidak memiliki episode yang panjang, dengan aktor dan aktris yang berbakat dan sangat menarik penampilannya, membuat drama seri ini menjadi awal pembuka bagi masuknya Korean Pop Culture lainnnya. Hal tersebut dibuktikan dengan ditayangkannya drama seri Korea lain yang berjudul Winter Sonata pada tahun yang sama pula. (Simbar, 2016). Merujuk teori tentang remaja (Aury \& Panuju, 2018), Menurut Piaget (dalam Hurlock, 2003) masa remaja adalah usia di mana individu berintegrasi dengan masyarakat dewasa, usia di mana anak tidak lagi merasa di bawah tingkat orang-orang yang lebih tua melainkan berada dalam tingkatan yang sama, sekurang-kurangnya dalam masalah hak. Hall (dalam Sarwono, 2008) mengatakan bahwa usia remaja adalah 12 
sampai 25 tahun. Dimana tahap ini dibagi menjadi 3 yaitu remaja awal, remaja madya, dan remaja akhir.

Remaja awal (Early Adolescence) seorang remaja pada tahap remaja awal berusia 12-15 tahun, dimana masa ini remaja masih terheran-heran akan perubahan yang terjadi pada tubuhnya sendiri dan dorongan-dorongan yang menyertai perubahan-perubahan itu. Kepekaan yang berlebihlebihan ini ditambah dengan berkurangnya kendali terhadap "ego".

Remaja Madya (Middle Adolescence) pada tahap ini remaja yang berusia 1518 tahun sangat membutuhkan kawan-kawan. Ia senang kalau banyak teman yang menyukainya. Ia berada dalam kondisi kebingungan karena ia tidak tahu harus memilih yang mana: peka atau tidak peduli, ramairamai atau sendiri, optimis atau pesimis, idealis atau materialis, dan sebagainya.

Remaja Akhir (Late Adolescence) pada tahap remaja akhir yang berusia 1925 tahun adalah masa konsolidasi menuju periode dewasa dan ditandai dengan pencapaian lima hal yaitu: (1) Minat yang makin mantap terhadap fungsi-fungsi intelek. (2) Egonya mencari kesempatan untuk bersatu dengan orang-orang lain dan dalam pengalaman-pengalaman baru. (3) Terbentuk identitas seksual yang tidak akan berbuah lagi. (4) Egosentrisme (terlalu memusatkan perhatian pada diri sendiri) diganti dengan keseimbangan antara kepentingan diri sendiri dengan orang lain. (5) Tumbuh "dinding" yang memisahkan diri pribadinya (private self) dan masyarakat (the public).

Penelitian ini merujuk pada remaja usia 15-18 tahun yang duduk di bangku Sekolah Menengah Atas (SMA) di Kota Cirebon, yang masuk pada kategori remaja madya. Pada Masa ini, pilihan remaja terhadap suatu minat atau hobi tertentu bisa jadi sangat terpengaruh oleh teman 
sebayanya. Selain dari rekan sebaya, tentunya perkembangan teknologi informasi dan pemberitaan media massa juga memberikan pengaruh terhadap remaja usia ini.

Hasil penelitian sebelumnya yang serupa dengan penelitian ini adalah penelitian yang dilakukan oleh Aida Setyowati (12 Januari 2014) tentang Pengaruh Budaya K-Pop Terhadap Remaja Indonesia. Metode yang digunakan dalam penelitian ini adalah metode kualitatif, dengan memakai pendekatan fenomenologi. Fenomenologi digunakan agar dapat diketahui persepsi pengaruh budaya K-pop tehadap remaja dan juga dapat diketahui dampak yang ditimbulkan budaya K-pop. Serta diketahui strategi-strategi yang dapat digunakan untuk mengantisipasi perilaku menyimpang.

Penelitian ini bertujuan untuk mengetahui dampak mencintai atau mengidolakan budaya K-pop secara berlebihan agar remaja indonesia tidak sampai melakukan hal-hal yang menyimpang. Dari hasil penelitian terbukti bahwa keberadaan budaya k-pop di Indonesia membawa dampak negatif yang menjadikan remaja Indonesia semakin malas. Dampak-dampak tersebut antara lain menjadikan remaja Indonesia lupa waktu dan mencintai budaya orang lain dibandingkan budaya sendiri.

Selanjutnya penelitian Ridaryanthi (2014) yang berjudul Bentuk Budaya Populer Dan Konstruksi Perilaku Konsumen Studi Terhadap Remaja, didapati hasil yaitu persepsi informan mengenai Korea yang mereka peroleh dari media massa, sebagian besar mengakui bahwa di benak mereka Korea adalah hiburan. Musik dan drama adalah dua hal, atau dapat disebut sebagai produk Hallyu. Selain itu Korea adalah pariwisata. Tidak ada dari mereka yang menyebutkan sedikit saja mengenai sejarah negara Korea, bagaimana terbentuknya, tentang pemerintahannya atau kondisi 
perekonomiannya. Bagaimana Korean Wave dengan produknya telah sedemikian merujuk pada persepsi tertentu yang berkaitan dengan komoditas: hiburan dan pariwisata sebagai bagian dari perekonomian dalam era globalisasi.

Menurut mereka, media hanya menyoroti mengenai pariwisata, artisartis, penampilan atau pakaian dan dandanan serta hal-hal yang bersifat hiburan, oleh karena itu persepsi yang muncul mengenai Korea pun tidak jauh dari apa yang mereka temukan dari media. Walau ada dari informan yang mengatakan pernah menonton tayangan yang berisi sejarah Korea, namun tidak banyak media yang memberikan informasi serupa itu. Kebanyakan dari yang mereka temukan adalah bersifat "gossip" atau hiburan belaka.

Dari media, khalayak setidaknya tahu mengenai hal baru, dalam penelitian ini berkaitan dengan kemunculan Korean Wave atau Hallyu yang seolah menjadi kiblat baru hiburan dan tren dunia, khususnya kawasan Asia.

\section{METODOLOGI PENELITIAN}

Jenis penelitian yang penulis gunakan adalah penelitian deskriptif kualitatif. Dalam bentuk penelitian kualitatif, penelitian tentang riset yang bersifat deskriptif dan cenderung menggunakan analisis. Dengan cara ini diharapkan penelitian penulis bisa menjadi penelitian yang benar dan tepat.

Data yang digunakan dalam penelitian ini berasal dari dua sumber sebagai berikut:

1. Data primer 
Data primer merupakan sumber data yang diperoleh langsung dari sumber pertama. Data ini didapat dari observasi dan diperoleh langsung dari tiap-tiap individu yang dijadikan sampel penelitian melalui pengajuan pertanyaan wawancara secara langsung dengan remaja SMA di Kota Cirebon.

2. Data sekunder

Data sekunder merupakan data yang diperoleh melalui studi kepustakaan, yaitu buku, karya ilmiah, jurnal dan makalah.

Teknik pengumpulan data yang penulis gunakan dalam penelitian ini adalah:

\section{Observasi}

Observasi dalam penelitian ini dilakukan oleh peneliti. Observasi dalam penelitian ini adalah observasi langsung yaitu penelitian dan pengamat melihat dan mengamati secara langsung, kemudian mencatat perilaku dan kejadian yang terjadi pada keadaan sebenarnya.

2. Wawancara

Wawancara dilakukan oleh peneliti untuk mendapatkan informasi dari narasumber. Wawancara pada penelitian ini menggunakan interview tidak berstruktur karena peneliti memandang model ini adalah yang paling luwes, di mana subyek diberi kebebasan untuk menguraikan jawabannya dan ungkapanungkapan pandangannya secara bebas dan sesuai harinya.

\section{Dokumentasi}

Teknik dokumentasi adalah teknik yang dipakai untuk memperoleh informasi melalui pengambilan gambar dari kamera, meliputi foto profil pribadi dan grup online yang berhubungan dengan pengaruh budaya Korea (K-pop).

Teknik analisis data yang penulis gunakan dalam penelitian ini adalah:

1. Pertama-tama mencari data dan referensi dari buku ataupun browsing di internet dan dari wawancara sederhana yang penulis lakukan. 
2. Memastikan bahwa semua data dan kajian teori yang diperlukan telah diperoleh dengan baik.

3. Mengklasifikasikan jawaban-jawaban dari tiap pertanyaan wawancara berdasarkan jumlah responden yang memilih.

4. Menghubungkan data-data yang satu dengan yang lain juga dengan kajian teori yang ada.

5. Menyusun laporan dalam bentuk karya tulis ini.

Penelitian ini dilakukan di MAN 1 Cirebon, Jalan Pilang Raya Sukapura Kejaksan Kota Cirebon dan beberapa tempat yang mejadi wadah bertemunya komunitas K-Pop di Cirebon. Perlu dijelaskan bahwa waktu yang dilaksanakan untuk penelitian ini selama kurang lebih satu bulan, mulai akhir bulan Juni sampai dengan pertengahan bulan Juli.

Tabel 1: Jadwal penelitian

\begin{tabular}{|l|c|}
\hline \multicolumn{1}{|c|}{ Kegiatan } & Waktu \\
\hline Observasi, Kajian Pustaka & 27 Juni - 4 Juli 2018 \\
\hline Wawancara & 4 Juli 2018 - 25 Juli 2018 \\
\hline Penyusunan laporan & 26 Juli 2018 - 10 Agustus 2018 \\
\hline
\end{tabular}

D. PEMBAHASAN

Dalam penelitian ini, dipilih informan berusia 15-18 tahun, yang duduk di bangku seklah menengah atas (SMA) di Kota Cirebon, penggemar budaya Korea Pop dan mengikuti perkembangan dengan bergabung pada Grup Online K-Pop. Hampir seluruh remaja yang menjadi informan, mengetahui apa itu budaya Korea (K-pop) karena enak didengar dan artisnya yang sangat menarik di kalangan remaja khusunya remaja wanita. Sehingga banyak remaja yang mencintai budaya Korea (K-pop) hal itu sangat terlihat ketika remaja hafal dengan lirik lagu dan sering menyanyikan di hadapan umum, kelas ataupun tempat lainnya. 
K-pop singkatan dari Korean Pop (musik pop Korea), adalah jenis musik populer yang berasal dari Korea Selatan. Jenis musik ini adalah jenis musik pop, banyak artis dan kelompok musik populer yang berasal dari Korea Selatan yang populer di dalam negeri dan di mancanegara. Kegandrungan pada musik K-pop merupakan bagian yang tak terpisahkan dari pada demam K-pop (Korean wave) diberbagai Negara, termasuk Indonesia. K-pop ada sejak tahun 1960-an yang muncul akibat pengaruh dari musik J-pop (Jepang Pop).

Pendapat informan ketika ditanya tentang arti budaya K-Pop bagi remaja seusia mereka, jawabannya adalah "Musik, Boy and Girl Band, Penghilang stres" dan informan menyukai K-Pop karena "Jenis/ Genre musik, bakat dan wajah artisnya yang ganteng, cantik, keren, serta memiliki hal yang baik."

"Arti K-Pop bagi saya adalah Musik, boy and girl band, penghilang stres pula. Saya ikuti perkembangan K-Pop sejak tahun 2011.Jenis influencer KPOP yang saya suka karena jenis musik dan artis (ganteng, cantik, keren), bagi saya punya sisi baik. Sebenarnya saya tidak terlalu suka budaya Korea, lebih suka Indonesia dan Jepang. Saya juga enggak fasih berbahasa Korea, tahu sedikit. Lagu KPOP favorit kebanyakan BTS! Saya gabung dalam komunitas ARMYINA (Indonesia), ARMYCIR (Cirebon). Kegiatan komunitas yang saya lakukan biasanya khusus anggota Army (Penggemar BTS) yang baru untuk memperkenalkan, lalu kami (akuEteman admin lainnya) mengklaifikasikan jika ada kejanggalan dalam personil BTS yang sedang gempar sekarang, lalu kami membahas teori baru untuk album BTS yang baru karena BTS akan comeback, lalu mereka banyak yang bertanya juga, lalu mereka sendiri juga banyak membahas BTS agar army (SD,SMP,SMA) agar mengerti menjadi army yang baik seperti apa untuk fandomnya yaitu BTS. Lalu disisi lain kamipun mempromosikan poster, boneka, sepatu, baju atau marchandise dari BTS untuk dijualbelikan jika memang ada 
yang sudah mempuyai bisnis onlinenya dan masih banyak lagi." (Aulya Nur Safira)

Untuk pecinta K-Pop budaya Korea Selatan punya daya tarik tersendiri. Ibarat efek samping dari menikmati musik dan drama Korea. Drama Korea inilah yang secara tidak sadar menjadi kampanye penyebaran budaya dan kulinernya. Di Cirebon, terdapat beberapa kedai atau tempat makan yang mengusung konsep Korean Style seperti Haebaragi dan Epen's Box. Kimbab, ramyeon, bulgogi, kimchi, daenjang Jjiggae, bibimbap serta samyang masuk dalam menu makanan yang tersedia di sana. (radarcirebon.com).

Kedai makan bernuansa Korea ini menjadi tempat yang menarik bagi pecinta budaya Korea, baik budaya tradisional maupun K-Pop. Tempat ini juga menarik para remaja untuk mencoba, sarana untuk berkumpul sesama penggemar K-Pop, mencicipi hidangan yang biasa mereka kenal dalam drama, film atau reality show Korea.

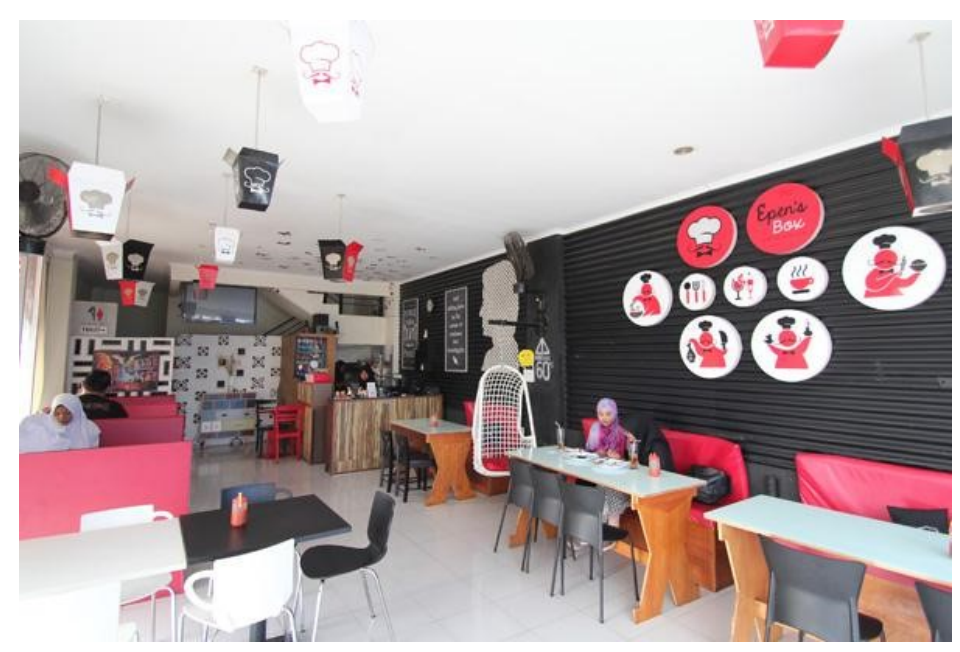

Gambar. Demam Korean Wave di Cirebon, bermunculan Kedai Lokal dengan yang kekinian dan sajian menu Korean Food.(Foto: Okriyana/Radarcirebon, 2016).

Di Cirebon, Demam Korean Wave juga ditemukan dengan munculnya beberapa komunitas remaja seperti Cirebon Kpop Dance Cover atau 
Cirebon Korean Dance Cover yang berlatih tari dan musik K-Pop. Mereka biasa berlatih di Cirebon Super Block (CSB) Mall, lantai dasar pada harihari tertentu.

Selain itu, adanya Grup Online yang diikuti oleh para informan yaitu: Grup di Google+ (BTS|ARMY, BTS|JUNGKOOK, BTS|KIM SEOKJIN, BTS | PARKJIMIN, BTS|SUGA, MIN YOONGI, BTS| ARMY, BTS ARMY, BTS V, BTS V@-, BTS LOVERS, EXO\&BTS, IKON, K-DRAMAS FOR LIVE, KIM TAEHYUNG, KOREAN DRAMA FANS<SHINEE, ARMY [BTS].

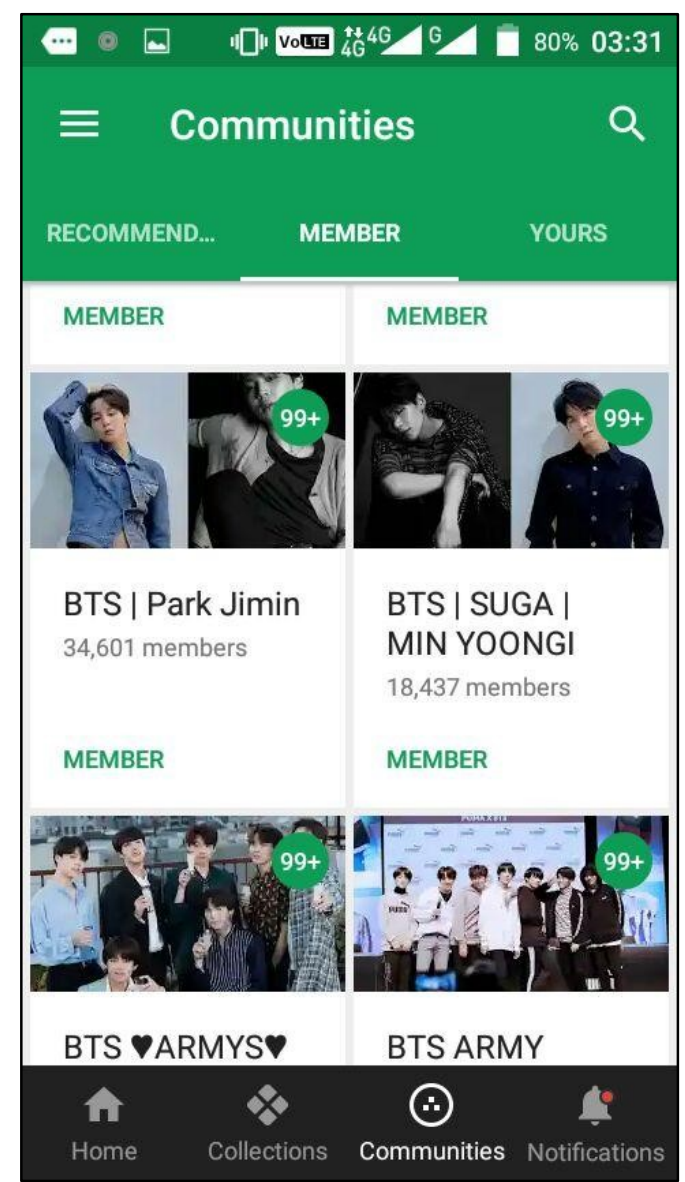




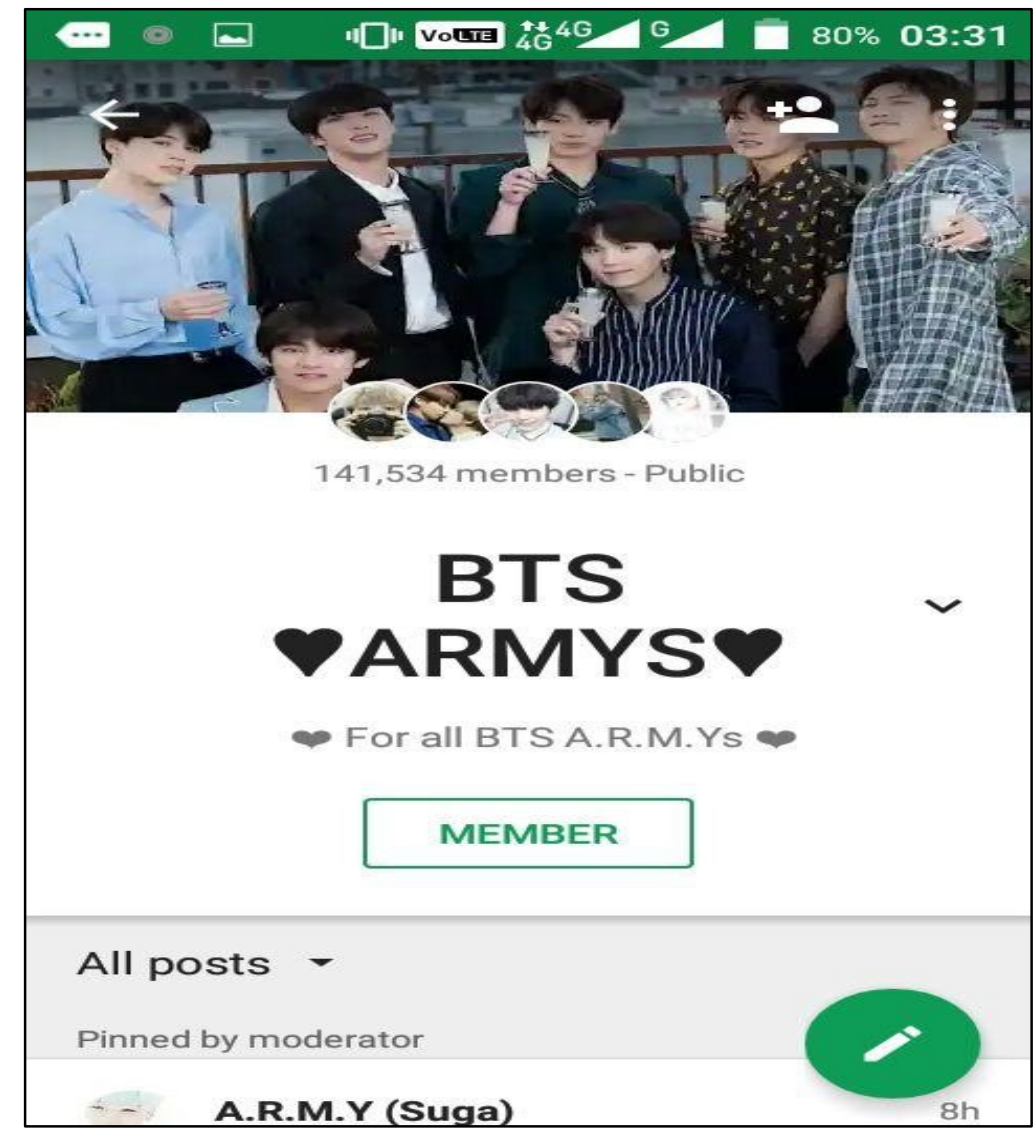

Gambar. Beberapa Grup Online K-Pop yang ada di Google +

Penggemar boyband asal Korea Selatan, Bangtan Boys (BTS) biasa disebut dengan ARMY. ARMY dianggap memiliki penggemar fanatik. Salah satunya, ketika konser ke Indonesia tahun 2014, para penggemarnya sampai menangis saat menyaksikan 2017 BTS Live Trilogy Episode III: The Wings Tour di Indonesia Convention Exhibition (ICE) BSD, Tangerang, Sabtu (29/4/2017) malam. (https:/ / entertainment.kompas.com/read/2017/04/30) 


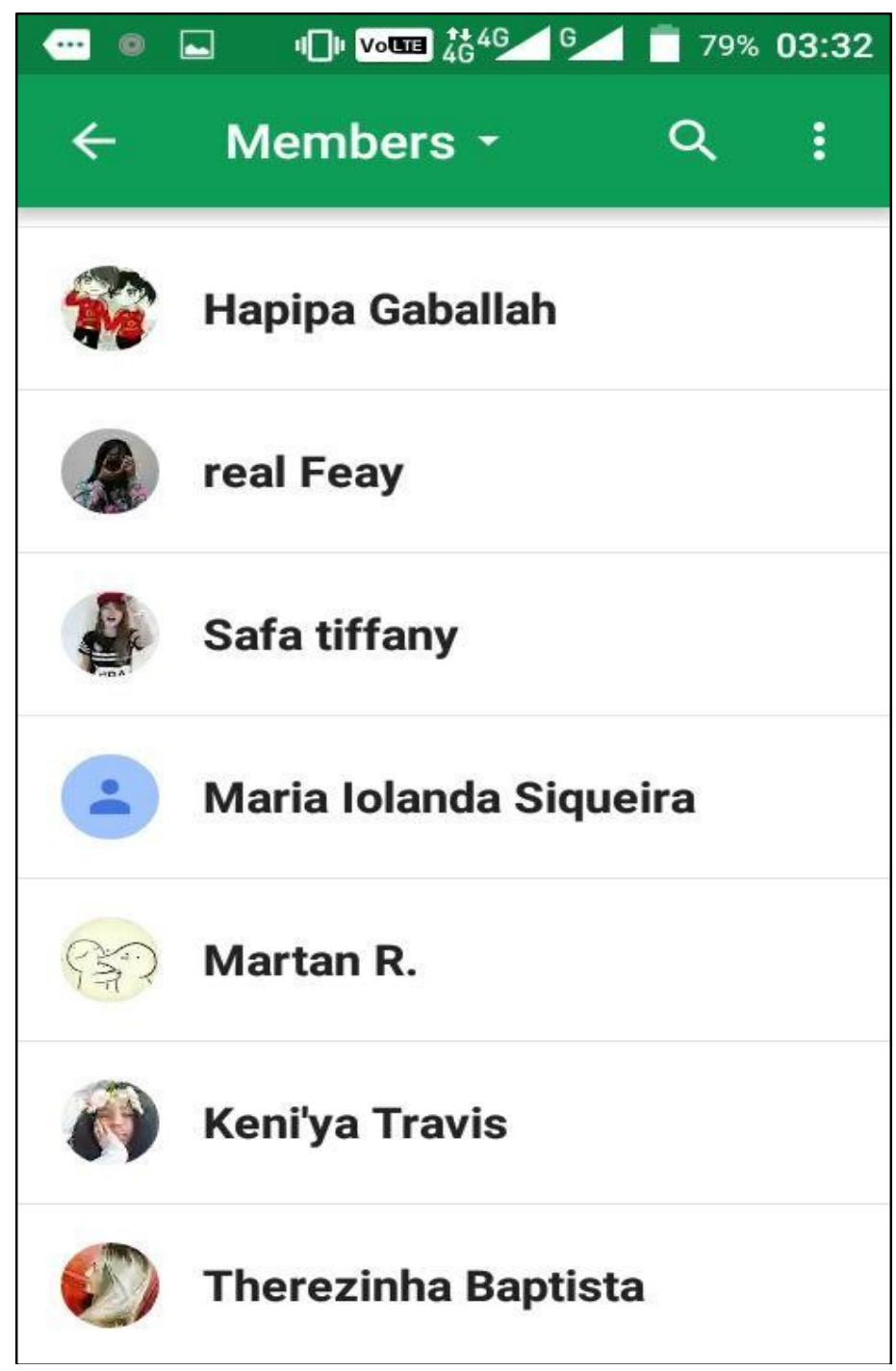

Gambar. Beberapa Member salahsatu Group Online KPOP di Google+, BTS ARMY

Keikutsertaan informan dalam komunitas K-Pop atau grup online K-Pop memberi

dampak dari segi positif maupun negatif. Dampak menjadi K-Popers bagi informan,

yaitu:

"Ada, untuk hal positifnya khususnya dari Kim Taehyung (salah satu personil BTS) dari sewaktu mereka debut (melalui menjadi BTS) pada Kim Taehyung sendiri banyak memberikan hal-hal positif seperti banyak memberikan motivasimotivasi secara tidak langsung. Lalu banyak suatu kejadian dari diri Taehyung yang secara nyata itu sama seperti aku. Lalu Taehyung itu anak dari seorang 
petani yang banyak memberikan motivasi dan semangat dan dari hari itu aku mulai tertarik akan Taehyung dan sampai sekarang. Dan masih banyak lagi tentang Taehyung, aku jadi seorang admin dari Armypun bisa menghasilkan keuntungan seperti bisa berjualan online dan lain-lain. Lalu untuk hal negatif hmmmm tekor di kuota wkwk, jarang tidur (sebenarnya mah memang insomnia hehee), mata minus karena liatin hp aja" (Aulya Nur Safira - Kelas XII, Member ARMY, Admin Grup Online Army-BTS Cirebon)

"Aku gak ikut komunitas K-POP. Tapi gabung di member Grup Online yang ada. Kurang lebih dampak positifnya jadi punya banyak temen, negatifnya jadi maen hp terus" (Oksaviani Azzuhra - Kelas XI, Anggota Grup Online K-Pop)

Menurut informan, dampak positif dari kesertaan mereka dalam Komunitas K-Pop dan atau Grup Online K-Pop, adalah:

1). Memberi motivasi dan semangat, karena kisah idolanya dianggap menginspirasi. 2). Menjadikan para remaja tersebut memiliki banyak hubungan pertemanan. Memiliki banyak teman atau menjadikan teman sebagai rujukan adalah ciri yang ada pada Remaja Madya (Middle Adolescence) seperti diungkapkan Piaget (Hurlock,2003) di atas.

3). Menghasilkan keuntungan dari penjualan online. 4)manfaat secara emosional, menyenangkan, menghilangkan stress bagi remaja.

Sedangkan khusus bagi kesertaan mereka dalam Grup Online, dampak negatifnya adalah:

1). Kesehatan mata, karena sering bermain ponsel.

2). Insomnia, kesulitan tidur.

3). Konsumtif, lebih boros.

Keterlibatan mereka dalam grup online ini menghabiskan pengeluaran yang cukup untuk mengakses informasi melalui internet. Meski informan 
menyukai K-Pop, namun mereka umumnya mengaku masih tahu dan menyukai budaya lokal daerah setempat, ketika ditanya, "Dengan menjadi seorang KPOPers masih adakah budaya lokal yang anda ketahui?", informan menjawab sebagai berikut:

Atuh masih, karena aku punya ponakan yang masih kecil jadi mendadak mesti ingat lagi untuk memberitahunya. Kaya tarling, tari topeng, batik, dan lainnya. (Aulya Nur Safira)

Ada dong, kaya sintren, tari topeng (Oksaviani Azzuhra)

Kebudayaan daerah yang dimiliki oleh Cirebon antara lain berupa tarian, kesenian musik, dan berbagai jenis kebudayaan lainnya yang kesemuanya sangat menarik dan sangat indah untuk dinikmati. Beberapa jenis kebudayaan yang dimiliki oleh Cirebon sebagian hanya dipentaskan pada saat acara - acara tertentu seperti upacara adat, namun ada juga yang sering dipentaskan untuk menarik perhatian para wisatawan yang berkunjung ke Cirebon.

Beberapa kebudayaan asli Cirebon tersebut diantaranya:

1) Tari Topeng. Salah satu kesenian yang ada di Cirebon adalah seni tari yang dikenal dengan nama tari topeng yang mana sesuai dengan namanya, sang penari akan memakai topeng, seni tari ini pada awalnya merupakan sebuah alat diplomasi yang digunakan ketika Kerajaan Cirebon sedang berperang melawan Kerajaan Karawang, sang penari dalam tarian topeng ini akan mengganti topengnya sesuai dengan karakter yang dibawakan.

2) Sintren, Kebudayaan kedua yang dimiliki oleh Cirebon adalah berupa sebuah kesenian tari yang dikenal dengan nama tari sintren di mana seni 
tari ini memiliki unsur magis, pada awal pertunjukan seni tari, sang penari akan diikat dari mulai leher hingga ujung kaki kemudian dimasukkan ke dalam sebuah kurungan yang ditutup dengan kain namun setelah itu ternyata sang penari dapat membebaskan diri dari ikatan tersebut (https://www.pusakapusaka.com/mengenalkebudayaan-asli-cirebon.html).

Sedangkan Tarling adalah pertunjukan seni rakyat yang merupakan singkatan gitar dan suling, yaitu pementasan cerita yang dipadukan dengan lagu-lagu Cirebonan.

Cirebon tumbuh dan berkembang menjadi kota penuh dengan warisan budaya dan sejarah yang menjadi bagian kebudayaan Cirebon. Di mana telah menjadi bagian penting dari kehidupan bangsa Indonesia dan tercatat sebagai situs sejarah nasional. Tentu saja, banyaknya potensi budaya yang ada di Cirebon, bukan hanya akan mendatangkan wisatawan, melainkan bisa terbukanya lapangan pekerjaan di bidang pariwisata. (http://www.asliindonesia.net/kebudayaan-cirebon/)

Merujuk pada perkembangan budaya dalam penelitian ini, Budaya melingkupi kreasi, transmisi, resepsi dan interpretasi iklan dan merek karena budaya menyentuh berbagai aspek konsumsi manusia (Semenik, 2012: 196). Dalam setiap budaya tersirat nilai-nilai yang dipahami dan dianut oleh masing-masing individu secara berbeda. Nilai-nilai yang terkandung dalam budaya ini abadi sifatnya, tidak mudah diubah (Semenik, 2012: 197 dalam Ridaryanthi, 2014).

Popularitas budaya Korea telah memberikan citra positif bagi konstruksi Asianization di seluruh dunia. Globalization dipahami sebagai hasil dari perjalanan modernitas dunia (Giddens 1991 dalam Doboo Shim 2011 
dalam Ridaryanthi, 2014). Hallyu atau Korean Wave sebagai suatu gejala budaya populer dunia telah dikonsumsi khalayak luas. Munculnya berbagai website tentang Korea dan produknya berupa musik dan film telah menarik perhatian banyak penggemar di seluruh dunia (Korean CultureAnd Information Service, 2011: 94 dalam Ridaryanthi, 2014).

Dalam penelitian ini, didapati beberapa remaja yang sejatinya menganggap budaya lokal atau nasional lebih disukai atau lebih mereka kenal, namun mereka pun tidak ingin ketinggalan mengikuti perkembangan sebagai penggemar budaya pop yang berasal dari Korea. Mereka beranggapan mengikuti perkembangan tersebut adalah sejalan dengan modernitas yang sedang marak. Ditambah lagi dengan adanya manfaat yang mereka dapatkan dari pilihan mereka menggemari K-Pop atau bergabung dengan Komunitas K-Pop tertentu baiki secara langsung maupun melalui media online.

\section{E. SIMPULAN}

Dari observasi, kajian pustaka dan wawancara yang dilakukan, didapatkan hasil dari penelitian ini adalah:

Pengaruh budaya Korea (K-pop) terhadap remaja Kota Cirebon adalah mengikuti Komunitas Fans K-Pop seperti ARMYINA, ARMYCIR atau Grup Online, seperti ( BTS|ARMY, BTS|JUNGKOOK, BTS|KIM SEOKJIN, BTS|PARKJIMIN, BTS|SUGA MIN YOONGI, BTS|ARMY, BTS ARMY, BTS V, BTS V@-, BTS LOVERS, EXO\&BTS, IKON, K-DRAMAS FOR LIVE, KIM TAEHYUNG, KOREAN DRAMA FANS < SHINEE, ARMY [BTS].

Selanjutnya, mengikuti aktivitas komunitas, atau informasi yang ada dalam grup tersebut. Para remaja pun menjadikan hal-hal berbau Korea 
seperti makanan Korea, Merchandise K-Pop, kedai makan Korea, dan sejenisnya sebagai hal yang menarik untuk dicoba. Meski pada akhirnya, mereka mengaku lebih menyukai budaya khas Indonesia dan masih mengenal budaya lokal Cirebon yang populer seperti Tarling, Tari Topeng, Kesenian Sintren hingga Batik.

Dampak yang ditimbulkan dari fanatisme budaya Korea (K-pop) terhadap remaja Kota Cirebon antara lain berdampak positif dan negative.

Menurut informan, dampak positif dari kesertaan mereka dalam Komunitas K-Pop dan atau Grup Online K-Pop, adalah:

1). Memberi motivasi dan semangat.

2). Memiliki banyak hubungan pertemanan,

3). Menghasilkan keuntungan dari penjualan online.

4). Manfaat secara emosional.

Sedangkan dampak negatifnya adalah:

1). Kesehatan mata.

2). Insomnia, kesulitan tidur.

3). Konsumtif, boros. 
Abdulsyani. 2007. Sosioogi Skematika, Teori, dan Terapan. Jakarta: Bumi Aksara Badan Standar Nasional Pendidikan. 2006. Satandar Kompetensi dan Kompetensi Dasar Mata Pelajaran Sosiologi untuk Sekolah Menengah Atas dan Madrasah Aliyah.

Aury, Shintya Oktaviany \& Redi Panuju. Efek Pemberitaan CCTV Lalu Lintas Terhadap Sikap Disiplin Berlalu Lintas dalam JIKE: Jurnal Ilmu Komunikasi Efek, Prodi Ilmu Komunikasi. Universitas Muhammadiyah Cirebon, Vol 1, No 2, Juni 2018.

http:// www.asliindonesia.net/kebudayaan-cirebon/

http://www.kaskus.us/showthread.php?p=593257227, 7 Desember 2015.

Hurlock. 1997. Remaja.

http:/ / www.radarcirebon.com/ada-suasana-korea-di-cirebon-annyeong-

haseyo.html

https:/ / entertainment.kompas.com/read/2017/04/30/193957710/a.r.m.y.indo

nesia.menangis.saat.menyaksikan.konser.bts

https://www.pusakapusaka.com/mengenal-kebudayaan-asli-cirebon.html

Johnson, Doyle Paul (penerjemah Robert MZ Lawang). 1986. Teori Sosiologi Klasik dan Modern Jilid I \& II, Jakarta: Gramedia.

Kuper, Adam (penerjemah Haris Munandar). 1996. Eksiklopedia Ilmu-Ilmu sosial. Jakarta: Raja Grafindo Persada.

Kusmantoro Muhammad, Hesti Jogan, Eka Yustinah. 2015. Sosiologi Kelas XII, Klaten: PT Intan Pariwara.

Riauzie Poetri, Milla. Dkk. Perilaku Konsumtif Remaja Perempuan Terhadap Trend Fashion Korea Di Jakarta Selatan .2014. Fakultas Ilmu Sosial Dan Ilmu Politik Universitas Udayana diakses melalui http:/ / download.portalgaruda.org/article.php?article=338107\&val=5805 \&title=perilaku $\%$ 20konsumtif $\%$ 20remaja $\%$ 20perempuan $\% 20$ terhadap $\% 20 t$ rend $\% 20$ fashion $\% 20$ korea $\% 20$ di $\% 20$ jakarta $\% 20$ selatan 
Ridaryanthi, Melly. Jurnal Visi Komunikasi Volume 13, No. 01, Mei 2014: 87-104. Bentuk Budaya Populer Dan Konstruksi Perilaku Konsumen Studi Terhadap Remaja diakses melalui https:/ / media.neliti.com/media/publications/142786-id-bentuk-budayapopuler-dan-konstruksi-per.pdf

Setyowati Aida, 2014, Pengaruh Budaya K-pop Terhadap Remaja Indonesia, http://blog.spot.com//12/01/14//Pengaruh Budaya K-pop Terhadap Remaja Indonesia, 7 Desember 2015.

Simbar, Frulyndese K. Jurnal Holistik, Tahun X No. 18 / Juli - Desember 2016 Issn 1979-0481 1 Fenomena Konsumsi Budaya Korea Pada Anak Muda Di Kota Manado diakses melalui https:/ / media.neliti.com/media/publications/80963-ID-fenomenakonsumsi-budaya-korea-pada-anak.pdf

Trihartanta, Agung, Eko Sujatmoko. 2012. Kamus Sosiologi. Surakarta: Aksara Sinerga Media.

Wawancara pribadi dengan Oksaviani Azzuhra dan Aulya Nur Safira, Juli 2018. 